Pesq. Vet. Bras. 37(7):657-661, julho 2017 DOI 10.1590/S0100-736X2017000700001

\title{
Taxa de infecção pelo Herpesvírus ovino tipo 2 (OvHV-2) em rebanhos de ovinos no Distrito Federal ${ }^{1}$
}

\author{
Rômulo S.A. Eloi², Tatiana G. Marçola², Giane R. Paludo³, Rebekah R. Araújo ${ }^{2}$ Edson \\ Moleta Colodel $^{4}$, Eduardo M.M. de Lima ${ }^{3}$ e Márcio B. Castro ${ }^{2 *}$
}

\begin{abstract}
Eloi R.S.A., Marçola T.G., Paludo G.R., Araújo R.R., Colodel E.M., Lima E.M.M. \& Castro M.B. 2017. [Ovine herpesvirus type 2 (OvHV-2) infection rate in sheep herds of the Federal District, Brazil.] Taxa de infecção pelo Herpesvírus ovino tipo 2 (OvHV-2) em rebanhos de ovinos no Distrito Federal. Pesquisa Veterinária Brasileira 37(7):657-661. Laboratório de Patologia Veterinária, Hospital Veterinário, Universidade de Brasília, Via L4 Norte, Cx. Postal 4508, Brasília, DF 70910-970, Brazil. E-mail: mbcastro@unb.br

Malignant catarrhal fever (MCF) is a disease caused by bovine infection with ovine herpesvirus type $2(\mathrm{OvHV}-2)$ and responsible for economic losses in different Brazilian regions. This paper describes the molecular detection of OvHV-2 by nested-PCR ( $n$ PCR) in nasal secretion/exfoliation samples and blood cell fraction (BCF) of sheep from 8 properties in the Federal District. Among the 188 nasal samples, 88 (41.5\%) were positive to OvHV-2. Pregnant ewe presented no differences at the infection rate in comparison with parous females. Newly calved sheep showed higher OvHV-2 infection rate than female over 60 days of calving. Nasal samples allowed the detection of infected animals by $n$ PCR with efficiency about twice than that in the blood cell fraction samples. In Brazil, epidemiological information about OvHV-2 infection in sheep flocks and factors involved in emergence of FCM outbreaks in cattle are still scarce. This study may provide support for elucidating some characteristics of the disease and for further epidemiological studies in the Federal District and other Brazilian States.
\end{abstract}

INDEX TERMS: Herpesvirus, OvHV-2, malignant catarrhal fever, PCR, sheep, diagnosis.

RESUMO.- A febre catarral maligna (FCM) é uma doença causada pela infecção de bovinos pelo herpesvírus ovino tipo 2 (OvHV-2), responsável por perdas econômicas em diferentes regiões do Brasil. Neste trabalho descreve-se a deteç̧ão molecular por nested-PCR ( $n$ PCR) do OvHV-2 em amostras de secreção/esfoliação nasal e fração celular sanguínea (FCS) de ovinos provenientes de 8 propriedades do Distrito Federal. Das 188 amostras nasais analisadas, 88 $(41,5 \%)$ foram positivas. Ovelhas prenhes não apresentaram diferenças na taxa de infecção em comparação com fêmeas paridas. Fêmeas recém-paridas apresentaram taxa de

\footnotetext{
${ }^{1}$ Recebido em 20 de outubro de 2016.

Aceito para publicação em 2 de abril de 2017.

${ }^{2}$ Laboratório de Patologia Veterinária, Hospital Veterinário, Universidade de Brasília (UnB), Via L4 Norte, Cx. Postal 4508, Brasília, DF 70910970, Brasil.*Autor para correspondência: mbcastro@unb.br

${ }^{3}$ Faculdade de Agronomia e Medicina Veterinária, UnB, Campus Darcy Ribeiro, Cx. Postal 4508, Brasília, DF 70910-970, Brasil.

${ }^{4}$ Programa de Pós-Graduação em Ciências Veterinárias, Faculdade de Medicina Veterinária, Universidade Federal de Mato Grosso, Cuiabá MT 78068-900, Brasil.
}

infecção pelo OvHV-2 maior que em animais que pariram há mais de 60 dias. Amostras de secreção/esfoliação nasal permitiram a detecção por $n$ PCR de animais infectados com uma eficiência aproximadamente duas vezes maior que em amostras de fração celular sanguínea. No Brasil, informações epidemiológicas sobre a infecção pelo OvHV-2 nos rebanhos ovinos e fatores envolvidos no surgimento de surtos de FCM em bovinos são escassos. Este estudo pode servir de subsídio para elucidar as características da enfermidade e para novos estudos sobre a epidemiologia da doença no Distrito Federal e em outros Estados do Brasil.

TERMOS DE INDEXAÇÃO: Herpesvírus, OvHV-2, febre catarral maligna, PCR, ovino, diagnóstico.

\section{INTRODUÇÃO}

A febre catarral maligna (FCM) é uma doença viral linfoproliferativa fatal de bovinos e outros ungulados (Russel et al. 2009). No Brasil, os casos de FCM em bovino estão vinculados à infecção pelo herpesvírus ovino tipo 2 (OvHV-2), sendo essa forma denominada "ovino associada" (Mendonça et 
al. 2008) e ocorre geralmente de forma esporádica em diferentes regiões brasileiras (Lemos et al. 2005, Mendonça et al. 2008, Galiza et al. 2010, Lucena et al. 2010, Furlan et al. 2012, Headley et al. 2012). 0 período de incubação em bovinos varia de 3 a 10 semanas e surgem sinais clínicos como distúrbios neurológicos, corrimento nasal mucopurulento, erosões e ulcerações em várias mucosas e febre (Garmatz et al. 2004, Mendonça et al. 2008, Furlan et al. 2012).

A epidemiologia da FCM ainda não é completamente esclarecida (Russell et al. 2009, O’Toole \& Li 2014), porém os casos são frequentemente vinculados à criação consorciada entre bovinos e ovinos portadores do OvHV-2 (Li et al. 2001, Russell et al. 2009) e, eventualmente, onde a criação é exclusivamente de bovinos (Furlan et al. 2012). No Brasil, pouco se conhece quanto à prevalência da infecção pelo OvHV-2 em rebanhos ovinos e há escassos estudos no mundo (Li et al. 1995, Mirangi \& Kang'ee 1997, Wani et al. 2006, Cortez et al. 2008, Loken et al. 2009, Bremer 2010, Giangaspero et al. 2013).

Alterações de manejo e estresse são considerados fatores cruciais para que o OvHV-2 saia da latência, passando a ser eliminado pelo ovino, propiciando a transmissão entre as espécies (Li et al. 2001). Eventos reprodutivos como gestação e parição são apontados como causa primária de estresse em ovelhas, propiciando condições para a eliminação viral no ambiente e o surgimento de casos em bovinos da FCM ovino-associada (Garmatz et al. 2004).

0 diagnóstico da infecção pelo OvHV-2 pode ser realizado por diferentes testes como o ensaio de imunoadsorção enzimática por inibição competitiva (CI-Elisa) e a reação em cadeia da polimerase (PCR), sendo a PCR, considerada o método mais eficiente (Li et al. 2001, Bremer 2010).

Os objetivos deste trabalho foram avaliar a taxa de infecção pelo OvHV-2 em rebanhos de ovinos no Distrito Federal (DF), determinar a influência da gestação e parição na taxa de infecção pelo OvHV-2 e comparar a eficácia das amostras de secreção/esfoliação colhidas com swab nasal e a fração celular sanguínea para detectar ovinos infectados pelo vírus por meio da nested-PCR.

\section{MATERIAL E MÉTODOS}

Oito rebanhos ovinos de pequeno a médio porte, localizados no Distrito Federal, foram selecionados aleatoriamente para este estudo. Nas oito propriedades avaliadas (P1 a P8), foram determinados o número total de ovelhas do rebanho (fêmeas acima de 18 meses de idade), idade média do plantel, tipo de alimentação/manejo na propriedade, período reprodutivo das matrizes, presença ou ausência de contato com bovinos, histórico de bovinos contactantes com sinais neurológicos e presença ou ausência de abrigo para os animais para proteção das variações climáticas diárias.

Nos plantéis, foram amostrados aleatoriamente 188 ovinos, fêmeas, em sua maioria mestiços da raça Santa Inês, entre maio e agosto de 2012, através da colheita de secreção e esfoliação da mucosa nasal com o uso de swab de algodão (Li et al. 2001), acondicionando-se as amostras em microtubos contendo $500 \mu \mathrm{L}$ de tampão fosfato salino $\mathrm{pH}$ 7,0 (PBS). Concomitantemente, foram colhidas desses mesmos animais, amostras de $3 \mathrm{~mL}$ de sangue em tubo contendo ácido etilenodiamino tetra-acético (EDTA) que posteriormente foram centrifugadas para a separação da fração celular sanguínea. Tanto as amostras obtidas com swab nasal, quanto as de fração celular sanguínea, foram armazenadas congeladas a $-20^{\circ} \mathrm{C}$ até analise. Foi realizada a extração do DNA das amostras de $s w a b$ nasal utilizando-se o kit QiAamp ${ }^{\circledR}$ DNAmini kit (QIAGEN) e da fração celular sanguínea o DNeasy ${ }^{\circledR}$ Blood \& Tissue Kit (QIAGEN). Para confirmação da extração e presença de DNA amplificável, foi realizado PCR específico para o gene do Gliceraldeído-3-fosfato desidrogenase (GAPDH) de todas as amostras (Birkenheuer et al. 2003).

A nested-PCR ( $n$ PCR) foi realizada utilizando-se os iniciadores 556 (AGTCTGGG-TATATGAATCCAGATGGCTCTC) e 755 (AAGATAAGCA-CCAGTTATGCATCTGATAAA) para primeira reação. Para a segunda reação, utilizou-se $1 \mu \mathrm{L}$ do produto da PCR primária e os iniciadores 556 e 555 (5'-TTCTGGGGTAGTGGCGAGCGAAGGCTTC-3') (Baxter et al. 1993). A amostra utilizada no controle positivo era proveniente de tecido incluído em parafina de um bovino previamente diagnosticado com febre catarral maligna (Mendonça et al. 2008). Para controle negativo, foi utilizada água deionizada e purificada pelo sistema mili-Q. A reação foi realizada no termociclador C1000 Thermal Cycler ${ }^{\circledR}$ (Bio Rad). As condições de amplificação para a primeira reação foram: $94^{\circ} \mathrm{C}$ por 7 minutos de desnaturação, 40 ciclos de $94^{\circ} \mathrm{C}$ por 1 minuto (desnaturação), $63^{\circ} \mathrm{C}$ por 1 minuto (anelamento), $72^{\circ} \mathrm{C}$ por 1 minuto (extensão). A segunda reação se diferenciou da primeira pela temperatura de anelamento de $67^{\circ} \mathrm{C}$. Produtos da segunda PCR foram submetidos à eletroforese em gel de agarose $2 \%$, corados com brometo de etídio e visualizados sob luz ultravioleta, resultando em um produto de 238 pares de base (pb) nos animais positivos. Os produtos de amplificação de três amostras aleatórias foram clonados e submetidos ao sequenciamento.

As taxas de infecção (TI) por OvHV-2 das ovelhas selecionadas foram determinadas em cada criatório e nos animais agrupados de acordo com os registros reprodutivos nas propriedades: fêmeas com até 60 dias de gestação; fêmeas acima de 60 dias de gestação; fêmeas com até 60 dias de paridas (FP1); fêmeas acima de 60 dias de paridas.

Para a determinação da amostra mais eficiente (swab nasal ou fração celular sanguínea) para a detecção da infecção por OvHV-2 em ovinos, foram selecionadas aleatoriamente 66 amostras positivas e 66 negativas na $n$ PCR de secreção/esfoliação colhidas com swab nasal. As amostras da fração celular sanguínea dessas mesmas ovelhas foram submetidas ao mesmo procedimento de detecção molecular do vírus para comparação.

As frequências das taxas de infecção foram submetidas ao teste Exato de Fisher, valor de $\mathrm{p} \leq 0,05$ com o programa PrismGraph 6.01.

\section{RESULTADOS}

As informações das propriedades, amostragem, rebanhos e suas taxas de infecção pelo OvHV-2 estão representadas no Quadro 1. 0 regime de criação instituído nas propriedades avaliadas era extensivo, as pastagens eram formadas predominantemente por Brachiaria spp. e a água fornecida à vontade. As amostras foram colhidas no período de estiagem no DF, com baixa umidade relativa do ar (menor que $20 \%$ ) e reduzido índice pluviométrico.

No total das amostras avaliadas de swab nasal $(\mathrm{n}=188)$ das ovelhas, houve uma taxa de infecção (TI) de 41,5\% $(\mathrm{n}=78)$ na análise da $n \mathrm{PCR}$ para OvHV-2, variando de $6,6 \%$ a $100 \%$ entre as propriedades. A TI foi maior na propriedade $\mathrm{P} 4$ que em todas as demais $(\mathrm{p} \leq 0,05)$, assim como na propriedade P5 que foi superior a P7 ( $p \leq 0,05)$. Os ovinos da propriedade P2 apresentaram taxa de infecção pelo OvHV-2 inferior ao observado nos criatórios P3, P4, P5 e P6 
Quadro 1. Informações clínico-epidemiológicas nos plantéis de ovelhas avaliados no Distrito Federal

\begin{tabular}{cccccc}
\hline Propriedade & OA (\%) & TI (\%) & IR (m) & CB & AB \\
\hline 1 & $53,3(40 / 75)$ & $32,5(13 / 40)$ & 24 & $\mathrm{~S}$ & $\mathrm{~S}$ \\
2 & $68,2(15 / 22)$ & $6,6(1 / 15)$ & 29 & $\mathrm{~S}$ & $\mathrm{~N}$ \\
3 & $85,4(47 / 55)$ & $46,8(22 / 47)$ & 36 & $\mathrm{~N}$ & $\mathrm{~S}$ \\
4 & $75,0(9 / 12)$ & $100(9 / 9)$ & 34 & $\mathrm{~S} *$ & $\mathrm{~N}$ \\
5 & $76,2(32 / 42)$ & $53,1(17 / 32)$ & 25 & $\mathrm{~N}$ & $\mathrm{~N}$ \\
6 & $73,5(25 / 34)$ & $52,0(13 / 25)$ & 23 & $\mathrm{~N}$ & $\mathrm{~N}$ \\
7 & $66,6(12 / 18)$ & $16,6(2 / 12)$ & 26 & $\mathrm{~S} *$ & $\mathrm{~N}$ \\
8 & $61,5(8 / 13)$ & $12,5(1 / 8)$ & 36 & $\mathrm{~S}$ & $\mathrm{~N}$
\end{tabular}

$\overline{\mathrm{OA}}=$ Percentual de ovelhas amostradas no rebanho. $\mathrm{TI}=$ Taxa de infecção. IR = Idade média dos animais do rebanho (em meses). $\mathrm{CB}=$ Contato de ovinos com bovinos. $\mathrm{S}=\mathrm{Sim}$. $\mathrm{N}=$ Não. ${ }^{*}$ Dividem o mesmo piquete com os ovinos. $\mathrm{AB}=$ propriedades com abrigos cobertos para os animais.

Quadro 2. Taxa de infecção pelo OvHV-2 de acordo com o estágio reprodutivo em ovelhas no DF

\begin{tabular}{lcc}
\hline & Até 60 dias & Acima de 60 dias \\
\hline Gestantes & $58,3 \%(7 / 12)^{\mathrm{a}}$ & $49,1 \%(28 / 57)^{\mathrm{a}}$ \\
Paridas & $56,7 \%(38 / 67)^{\mathrm{a}}$ & $28,8 \%(15 / 52)^{\mathrm{b}}$ \\
\hline
\end{tabular}

Letras diferentes na mesma linha indicam diferença significativa $(\mathrm{p}=0,003)$.

$(p \leq 0,05)$. As demais comparações entre os resultados das propriedades não apresentaram diferenças significativas $(p>0,05)$.

As frequências de animais positivos entre fêmeas gestantes $(50,7 \%)$ e paridas $(44,5 \%)$ foram semelhantes $(p>0,05)$. Entre os grupos de ovelhas avaliados de acordo com o estágio reprodutivo (Quadro 2), somente fêmeas com até 60 dias de paridas apresentaram TI pelo OvHV-2 maior que as fêmeas com mais de 60 dias de paridas $(\mathrm{p} \leq 0,05)$.

Entre as propriedades visitadas, somente $25 \%(\mathrm{n}=2)$ contavam com abrigo coberto para proteção dos animais das alterações climáticas diárias. As taxas de infecção (TI) pelo OvHV-2 nos ovinos amostrados nas propriedades com abrigos foram de $42,0 \%$ e de $52,5 \%$ nos criatórios sem esses abrigos, no entanto, essas diferenças não foram significativas ( $\mathrm{p}>0,05)$.

A criação consorciada entre ovinos e bovinos foi observada em cinco propriedades. Em três dessas, não havia contato direto entre as espécies, uma vez que os animais compartilhavam o piquete em temporadas distintas. Somente em duas delas, a criação das espécies era conjunta, permitindo contato direto entre os animais. Não foram relatadas ou observadas alterações neurológicas ou morte de bovinos nos últimos três anos naquelas propriedades, ou outros sinais clínicos compatíveis com os descritos em casos de FCM.

A comparação entre os resultados das amostras de swab nasal e de sangue dos mesmos animais, demonstrou que menos da metade $(48,5 \%, n=32)$ das 66 amostras sanguíneas foram positivas $(\mathrm{p} \leq 0,05)$. Todas as 66 ovelhas negativas nas amostras colhidas com swab nasal também apresentaram resultados idênticos na avaliação da fração celular sanguínea.

As análises do sequenciamento das três amostras aleatórias apresentaram 99\% de similaridade com as sequên- cias do gene ORF75 do OvHV-2 depositadas no GenBank (EU851175.1, EU851177.1, KU499857.1).

\section{DISCUSSÃO}

O presente estudo com ovinos do DF demonstrou que todos os rebanhos e aproximadamente metade dos animais amostrados (46,8\%) apresentaram a infecção pelo OvHV-2. A prevalência de ovinos portadores desse vírus pode apresentar grande variação de acordo com a região estudada e 0 tipo de teste utilizado. Testes moleculares detectaram índices de infecção pelo vírus em ovinos bastante variáveis em outras partes do mundo como $77 \%$ na África do Sul (Bremer 2010), 70,5 \% em Portugal (Cortez et al. 2008), 84,8\% na Índia (Wani et al. 2006) e 99 \% nos Estados Unidos (Li et al. 1995). 0 levantamento da infecção pelo OvHV-2 em ovinos do DF não possibilitou identificar as razões pelas quais as taxas de infecção nos rebanhos foram inferiores ao observado em outros países.

Ao comparar individualmente as propriedades, foram observadas diferenças $(p \leq 0,05)$ principalmente entre os criatórios com as taxas de infecção mais elevadas daquelas com os menores valores. É provável que variações no manejo instituído no rebanho possam ter influenciado nos resultados, de forma semelhante ao encontrado na África do Sul (Bremer 2010). Entretanto, as informações e valores determinados nos rebanhos do DF não foram suficientes para apontar os fatores envolvidos nessas diferenças.

Não foram observadas diferenças na TI entre fêmeas gestantes e paridas nos rebanhos analisados. Entretanto, comparando-se os subgrupos, ovelhas recém-paridas apresentaram taxa de infecção maior que o grupo de ovelhas paridas há mais de 60 dias. Esse resultado sugere que fêmeas recém-paridas poderiam apresentar maior eliminação de partículas virais para o ambiente, aumentando o risco de transmissão da FCM. Ovelhas paridas foram consideradas inicialmente capazes de apresentar maior quantidade de partículas virais em amostras de swab nasal (Li et al. 2001), no entanto, foi demonstrado posteriormente não haver diferenças significativas entre a eliminação viral na secreção nasal de fêmeas paridas e não-paridas na transmissão da FCM (Li et al. 2004). 0 estresse gestacional em ovelhas é considerado fator que propicia a ativação viral e sua propagação (Baxter et al. 1997) e, por essa razão, fêmeas ovinas são mais frequentemente vinculadas à transmissão da doença para os bovinos (Garmatz et al. 2004, Furlan et al. 2012).

Em cinco propriedades visitadas, onde havia criação conjunta (direta ou indireta) de ovinos com bovinos, não foram relatados casos de FCM ou outras enfermidades com sinais neurológicos nos rebanhos. Esses achados demonstram que a predisposição ambiental e de manejo atribuída frequentemente a casos de febre catarral maligna (Abu Elzein et al. 2003, Rech et al. 2005), nem sempre são suficientes para explicar o surgimento ou não da doença. Uma possível explicação para a não ocorrência da FCM nas propriedades poderia estar associada à eliminação de níveis infectantes insuficientes pelos ovinos, para causar a doença nos bovinos (Taus et al. 2006).

A TI nos rebanhos ovinos do DF foi menor que a observada em outros países e isso poderia explicar um risco me- 
nor de transmissão da FCM e a ausência de casos da doença nos bovinos nos mesmos criatórios avaliados. Também é importante considerar que as condições de período seco prolongado, característico do clima da região, poderiam dificultar a transmissão do vírus entre os animais do rebanho. A eliminação de partículas virais pelos ovinos pode ser influenciada pelas variações ou condições ambientais (Bremer 2010).

A exposição direta dos animais às variações climáticas diárias devido à ausência de estrutura de proteção (abrigos cobertos) é um fator importante a ser considerado e que poderia influenciar os resultados observados. Aproximadamente $50 \%$ de todos os animais dos rebanhos estudados $(\mathrm{n}=130)$ estavam expostos diretamente às condições climáticas pela ausência de abrigos, entretanto, não houve diferenças na TI $(p>0,05)$ entre as propriedades, demonstrando que nas condições desse estudo, isso não foi relevante. 0 estresse é considerado fator crucial para que ocorra a eliminação de partículas virais pelos ovinos, porém pouco se sabe sobre a relação dos seus diversos fatores causais (Furlan et al. 2012). Apesar das condições de calor e baixa umidade que ocorreu no Distrito Federal no período avaliado, os rebanhos eram formados em sua maioria por mestiços da raça Santa Inês provenientes de plantéis do Nordeste Brasileiro, considerados bem adaptados às condições de seca (Veríssimo et al. 2009).

As amostras sanguíneas são utilizadas com frequência na detecção molecular de ovinos infectados pelo OvHV-2 (Baxter et al. 1993, Li et al. 1995, Wani et al. 2006, Loken et al. 2009, Bremer 2010, Dabak et al. 2012). Entretanto, os resultados obtidos com os ovinos no DF demonstraram uma maior eficiência das amostras colhidas com swab nasal para a detecção molecular do OvHV-2, quando comparadas com a fração celular sanguínea, em acordo às observações anteriores (Li et al. 2001, Li et al. 2004).

A maior positividade de ovinos na $n$ PCR para o vírus em amostras de secreção nasal neste estudo reforça a importância das vias aéreas na eliminação do OvHV-2 (Kim et al. 2003, Li et al. 2004, Taus et al. 2005, Taus et al. 2006, Gailbreath et al. 2008). A transmissão experimental do vírus entre ovinos pode ser realizada através da inoculação de grandes volumes de sangue $(100 \mathrm{ml})$ e ocorre em apenas em $50 \%$ dos animais (Li et al. 2000). Porém, a espécie é capaz de apresentar períodos de eliminação de elevadas cargas virais por aerossóis e secreções nasais e infectar experimentalmente todos os ovinos expostos (Taus et al. 2005). Esses achados poderiam justificar a maior eficiência do swab nasal para detectar animais positivos neste experimento.

A FCM é uma enfermidade que apresenta fatores epidemiológicos e patogenia ainda não completamente elucidados, que dificultam a compreensão do surgimento de surtos em bovinos. No Brasil, a FCM ovino-associada é a principal forma da doença e pode aumentar sua importância em decorrência da disseminação da ovinocultura no território nacional, que eleva o risco dos rebanhos bovinos à exposição ao OvHV-2. Os resultados obtidos são pioneiros na região, fornecendo informações epidemiológicas sobre alguns fatores predisponentes e amostrais importantes, servindo de base para futuros estudos da FCM em rebanhos bovinos.

\section{CONCLUSÕES}

Este estudo com ovinos no DF demonstrou que em todos os rebanhos e em aproximadamente metade dos animais da região ocorre a infecção pelo OvHV-2.

Esses achados demonstram a importância de ovinos na manutenção do vírus e sempre deve ser considerado o risco que representam na transmissão da FCM para bovinos, como observado em outras regiões brasileiras.

A TI pelo vírus foi semelhante entre ovelhas gestantes e paridas neste estudo, e reforça a existência do risco de transmissão do OvHV-2 independente do estágio gestacional ou de parição.

A colheita de amostras de secreção/esfoliação nasal permite detectar a infecção pelo OvHV-2 pela $n \mathrm{PCR}$ em ovinos com uma eficiência aproximadamente duas vezes maior que a obtida com amostras de fração celular sanguínea.

Agradecimentos.- Ao Conselho Nacional de Pesquisa (CNPq), pelo suporte financeiro.

\section{REFERÊNCIAS}

Abu Elzein E.M.E., Housawi F.M.T., Gameel A.A., Al-Afaleq A.I. \& El-Bashir A.M. 2003. Sheep-associated malignant catarrhal fever involving 3-5week-old calves in saudi arabia. J. Vet. Med. Sci. 50:53-59.

Baxter S.I.F., Pow I., Bridgen A. \& Reid H.W. 1993. PCR detection of the sheep-associated agent of malignant catarrhal fever. Arch. Virol. 132: 145-159.

Baxter S.I.F., Wiyono A., Pow I. \& Reid H.W. 1997. Identication of ovine herpesvirus-2 infection in sheep. Arch. Virol. 142:823-831.

Birkenheuer A.J., Levy M.G. \& Breitschwerdt E.B. 2003. Development and evaluation of a seminested PCR for detection and differentiation of $\mathrm{Ba}$ besia gibsoni (Asian genotype) and B. canis DNA in canine blood samples. J. Clin. Microbiol. 41:4172-4177.

Bremer C.W. 2010. The prevalence of ovine herpesvirus-2 in 4 sheep breeds from different regions in South Africa. J. South African Vet. Med. Assoc. 81:93-96.

Cortez P.P., Carvalheira J., Paupério S. \& Thompson G. 2008. Prevalence of ovine herpesvirus type 2 in north-west Portugal. Vet. Rec. 162:282-284.

Dabak M., Dabak D.O., Karapinar T. \& Bulut H. 2012. Vitamin D status in cattle with malignant catarrhal fever. J. Vet. Med. Sci. 74:125-128.

Furlan F.H., Amorim T.M., Justo R.V., Mendes E.R.S., Zilio M.G., Costa F.L., Nakazato L. \& Colodel E.M. 2012. Febre catarral maligna em bovinos no norte de Mato Grosso. Acta Scient. Vet. 40:1043.

Galiza G.J.N., Silva M.L.C.R., Dantas A.F.M., Simões S.V.D. \& Riet-Correa Franklin. 2010. Doenças do sistema nervoso de bovinos no semiárido nordestino. Pesq. Vet. Bras. 30:267-276.

Garmatz S.L., Irigoyen L.F., Rech R.R., Brown C.C., Zhang J. \& Barros C.S. L. 2004. Febre catarral maligna em bovinos no Rio Grande do Sul: transmissão experimental para bovinos e caracterização do agente etiológico. Pesq. Vet. Bras. 24:93-106.

Gailbreath K.L., Taus N.S., Cunha C.W., Knowles D.P. \& Li H. 2008. Experimental infection of rabbits with ovine herpesvirus 2 from sheep nasal secretions. Vet. Microbiol. 132:65-73.

Giangaspero M., Savini G., Osawa T. \& Harasawa R. 2013. Serological survey to determine the occurrence of malignant catarrhal fever infection in the japanese small ruminant population from Northern Districts. J. Vet. Med. Sci. 75: 815-818.

Headley A.S., Sousa I.K.F., Minervino A.H.H., Barros I.O., Junior R.A.B., Alfieri A.F., Ortolani E.L. \& Alfieri A.A. 2012. Molecular confirmation of ovine 
herpesvirus 2-induced malignant catarrhal fever lesions in cattle from Rio Grande do Norte, Brazil. Pesq. Vet. Bras. 32:1213-1218.

Kim O., Li H. \& Crawford T.B. 2003. Demonstration of sheep-associated malignant catarral fever virions in sheep nasal secretions. Virus Res. 98:117-122.

Lemos R.A.A., Rech R.R., Guimarães E.B., Kadri A. \& Dutra I.S. 2005. Febre catarral maligna em bovinos do Mato Grosso do Sul e de São Paulo. Ciência Rural 35:932-934.

Li H., Shen D.T., Toole D.O., Knowles D.P., Gorham J.R. \& Crawford T.B. 1995. Investigation of sheep-associated malignant catarrhal fever virus infection in ruminants by PCR and competitive inhibition enzyme-linked immunosorbent assay. J. Clin. Microbiol. 33:2048-2053.

Li H., Snowder G., O’Toole D.T. \& Crawford T.B. 2000. Transmission of ovine herpesvirus 2 among adult sheep. Vet. Microbiol. 71:27-35.

Li H., Hua Y., Snowder G. \& Crawford T.B. 2001. Levels of ovine herpesvirus 2 DNA in nasal secretions and blood of sheep: implications for transmission. Vet. Microbiol. 79:301-310.

Li H., Taus N.S., Lewis G.S., Kim O., Traul D.L. \& Crawford T.B. 2004. Shedding of ovine herpesvirus 2 in sheep nasal secretions: the predominant mode for transmission. J. Clin. Microbiol. 42:5558-5564.

Loken T., Bosman A.M. \& Vuuren M.V. 2009. Infection with ovine herpesvirus 2 in Norwegian herds with a history of previous outbreaks of malignant catarrhal fever. J. Vet. Diagn. Invest. 21:257-261.

Lucena R.B., Pierezan F., Kommers G.D., Irigoyen L.F., Fighera R.A. \& Barros C.S.L. 2010. Doenças de bovinos no Sul do Brasil: 6.706 casos. Pesq. Vet. Bras. 30:428-434.
Mendonça F.S., Dória R.G.S., Schein F.B., Freitas S.H., Nakazato L., Boabaid F.M., Paula D.A.J., Dutra V. \& Colodel E.M. 2008. Febre catarral maligna em bovinos no Estado de Mato Grosso. Pesq. Vet. Bras. 28:155-160.

Mirangi P.K. \& Kang'ee F.M. 1997. Detection of ovine herpesvirus 2 in Kenyan sheep by polymerase chain reaction. Vet. Rec. 141:176-177.

O'Toole D. \& Li H. 2014. The pathology of malignant catarrhal fever, with an emphasis on ovine herpesvirus 2. Vet. Pathol. 51:437-452.

Rech R.R., Schild A.L., Driemeier D., Garmatz S.L., Oliveira F.N., Riet-Correa F. \& Barros C.S.L. 2005. Febre catarral maligna em bovinos no Rio Grande do Sul: epidemiologia, sinais clínicos e patologia. Pesq. Vet. Bras. 25:97-105.

Russell G.C., Stewart J.P. \& Haig D.M. 2009. Malignant catarrhal fever: a review. Vet. J. 179:324-335.

Taus N.S., Traul D.L., Oaks J.L., Crawford T.B., Lewis G.S. \& Li H. 2005. Experimental infection of sheep with ovine herpesvirus 2 via aerosolization of nasal secretions. J. Gen. Virol. 86:575-579.

Taus N.S., Oaks J.L., Gailbreath K., Traul D.L., O’Toole D. \& Li H. 2006. Experimental aerosol infection of cattle (Bos taurus) with ovine herpesvirus 2 using nasal secretions from infected sheep. Vet. Microbiol. 116:29-36.

Veríssimo C.J., Titto C.G., Katiki L.M., Bueno M.S., Cunha E.A., Mourão G.B., Otsuk I.P., Pereira A.M.F., Nogueira Filho J.C.M. \& Titto E.A.L. 2009. Tolerância ao calor em ovelhas Santa Inês de pelagem clara e escura. Revta Bras. Saúde Prod. Anim. 10:159-167.

Wani S.A., Samanta I., Pandit F., Buchoo B.A., Peer F. \& Bhat M.A. 2006. Molecular epidemiology of ovine herpesvirus type 2 infection in Kashmir, India. Vet. Rec. 159:587-590. 